\title{
Forced electrostriction by constraining polarization switching enhances the electromechanical strain properties of incipient piezoceramics
}

\author{
Chang Won Ahn ${ }^{1}$, Gangho Choi ${ }^{1}$, Ill Won Kim ${ }^{1}$, Jae-Shin Lee $^{2}$, Ke Wang ${ }^{3}$, Younghun Hwang ${ }^{4}$ and Wook Jo ${ }^{4}$ \\ Recently developed lead-free incipient piezoceramics are promising candidates for off-resonance actuator applications due to \\ their exceptionally large electromechanical strains. Their commercialization currently faces three critical challenges: the high \\ driving electric field required for delivering the potentially large strains; large strain hysteresis, which is inappropriate for \\ precision devices; and relatively high temperature dependencies. We propose that instead of utilizing incipient piezoelectric \\ strains, harnessing the maximum possible electrostriction would provide a highly effective way to resolve all these challenges. \\ This concept was experimentally demonstrated using textured $0.97 \mathrm{Bi}_{1 / 2}\left(\mathrm{Na}_{0.78} \mathrm{~K}_{0.22}\right)_{1 / 2} \mathrm{TiO}_{3}-0.03 \mathrm{BiAlO}_{3}$ as an exemplary \\ incipient piezoceramic, whereby texturing was achieved using a reactive templated grain-growth technique. The manufactured \\ textured ceramic is characterized by $S_{\max } / E_{\max }$ of $995 \mathrm{pm} \mathrm{V}-1$ and an electrostrictive coefficient, $Q_{33}$, of $0.049 \mathrm{~m}^{4} \mathrm{C}^{-2}$. Both \\ these parameters are as large as those of single crystals. The current work presents a significant advancement in the field \\ of lead-free ceramics and can guide future efforts in this direction. In addition, the concept presented here can be easily \\ transferred to other disciplines involving the design of functional properties of various materials.
}

NPG Asia Materials (2017) 9, e346; doi:10.1038/am.2016.210; published online 27 January 2017

\section{INTRODUCTION}

Since the first report on incipient piezoelectric strain (IPS) in a $\left(\mathrm{Bi}_{1 / 2} \mathrm{Na}_{1 / 2}\right) \mathrm{TiO}_{3}$ (BNT)-based lead-free ceramic, ${ }^{1}$ there have been numerous attempts to enhance the strain properties of these materials. These studies have concluded that IPS is a common feature of relaxor ferroelectrics as long as their freezing temperature is below room temperature, that is, they are in the ergodic relaxor state, whereas ferroelectric long-range order is only stable under the application of a certain or higher electric field. ${ }^{2-4}$ It should be noted that the electric-field-induced strain in a normal ferroelectric material is approximately half the strain inherently available for the given system. This result is due to the presence of the remanent state, which typically occupies $\sim 0.1 \%$ of the entire phase. ${ }^{2}$ Piezoelectric strain commonly refers to the difference between the maximum and remanent strain levels, and it may be greatly enhanced by minimizing the remanent strain, as is the case for IPS.

Thus far, most useful IPSs have been found in relaxor ferroelectrics, ${ }^{3,5}$ indicating that the inherently large poling field, $E_{\mathrm{pol}}$, (poling field: an electric field required for inducing ferroelectric state out of the existing relaxor state, determined at the inflection point of the electric-field-dependent strain curve as illustrated in Figure 1a) with a consequently large hysteresis, is unavoidable. This result is due to the considerably large nucleation energy barrier that has to be overcome for a ferroelectric phase to be born in a pure relaxor phase. In addition, the temperature-dependent strain properties are commonly expected to be poor because the electric field for a relaxor-to-ferroelectric transition increases significantly with temperature. ${ }^{6,7}$ This finding means that the driving electric field must be accordingly increased with increasing temperature to preserve the expected strain values. However, such an effect is practically impossible to achieve due to the simultaneous decrease in the breakdown electric field. Therefore, the strain characteristics of samples prepared by conventional solid-state reaction (CSSR) methods have a series of challenges to overcome, including large hystereses, large driving electric fields and relatively large temperature dependence. It follows that for incipient piezoceramics to be of practical importance, the three challenging issues, that is high $E_{\mathrm{pol}}$, large degree of hysteresis and poor temperature stability, must be overcome reliably. ${ }^{2,3}$

Considering the mechanism for IPS, a potentially simple solution to the aforementioned challenges could be via the control of the nucleation kinetics of the electric-field-induced ferroelectric

\footnotetext{
${ }^{1}$ Department of Physics and EHSRC, University of Ulsan, Ulsan, Republic of Korea; ${ }^{2}$ School of Materials Science and Engineering, University of Ulsan, Ulsan, Republic of Korea; ${ }^{3}$ State Key Laboratory of New Ceramics and Fine Processing, School of Materials Science and Engineering, Tsinghua University, Beijing, People's Republic of China and ${ }^{4}$ School of Materials Science and Engineering, Ulsan National Institute of Science and Technology, Ulsan, Republic of Korea

Correspondence: Professor IW Kim, Department of Physics and EHSRC, University of Ulsan, Ulsan, Republic of Korea.

E-mail: kimiw@ulsan.ac.kr

or Professor W Jo, School of Materials Science and Engineering, Ulsan National Institute of Science and Technology, 50 UNIST-gil, 102-601-4, Ulsan 44919, Republic of Korea. E-mail: wookjo@unist.ac.kr

Received 10 September 2016; revised 21 October 2016; accepted 14 November 2016
} 
a

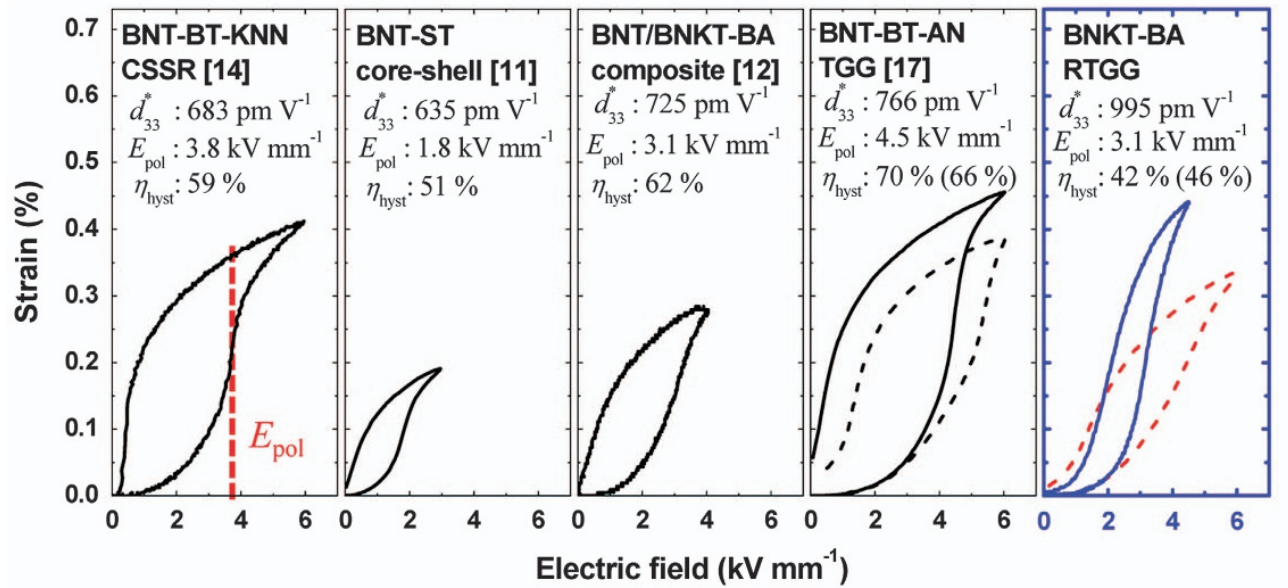

b

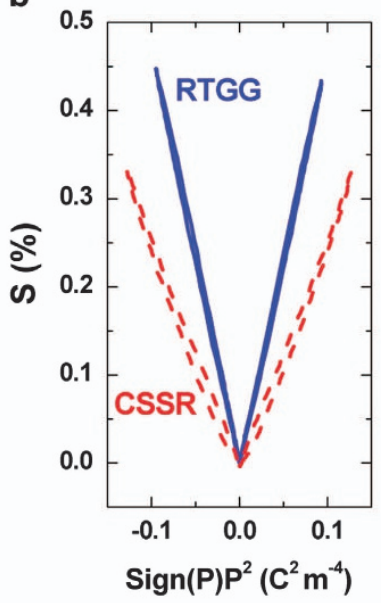

C

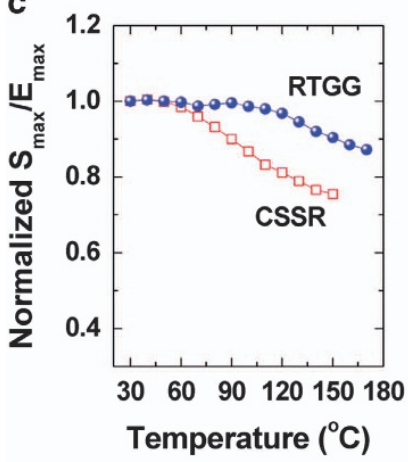

d

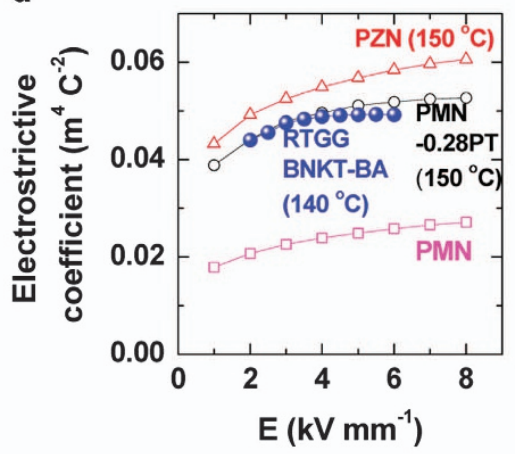

e

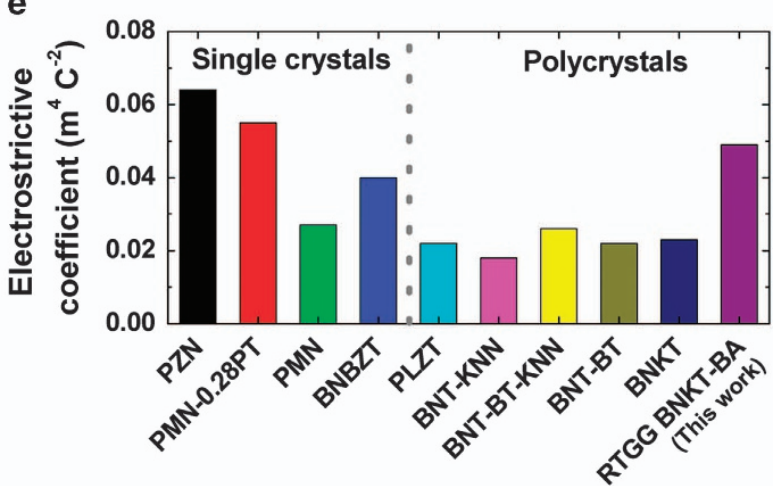

Figure 1 (a) Strain versus electric field plots for the materials of interest in the literature, exemplarily selected for each technique, compared with that of the currently developed RTGG piezoceramic. The dotted lines in the TGG and RTGG plots refer to the strain curve of a randomly oriented ceramic sample of the same composition. (b) $S$ versus $P^{2}$ plot showing a quadratic dependence of $S$ on $P$, which is a fingerprint for electrostriction. (c) The highly stable temperature-dependent strain property of the RTGG specimen compared with that of the CSSR specimen confirms that the electromechanical strain comes mainly from electrostriction. (d) The electrostrictive coefficient, $Q_{33}$, as a function of the excitation electric field, compared with that of lead-based relaxor single crystals. (e) A summary of the electrostrictive coefficient of representative perovskite materials compared with that of the RTGG specimen. (All the electrostrictive data were measured at room temperature, except for PZN \& PMN-0.24PT, which were measured at $150{ }^{\circ} \mathrm{C}$ ).

phase formation out of the initial relaxor phase. ${ }^{8}$ A common strategy used to facilitate the electric-field-induced relaxor-to-ferroelectric transition includes the tailoring of microstructures. A breakthrough in the form of experimental validation of this strategy was made with the design of a heterogeneous microstructure consisting of a ferroelectrically active core and a paraelectric shell. Here the core acted as a ferroelectric nucleus. ${ }^{9}$ This core-shell approach seems ideal for resolving the challenges of IPS. However, it suffers from a disadvantage, namely that it is difficult to achieve precise control over the composition of the core and the shell., ${ }^{6,9}$

Recently, a 0-3 type ceramic-ceramic composite approach has been proposed as an alternative technique to the core-shell structure. The expected outcome of this approach is the same as that of the core-shell approach. ${ }^{10-12}$ One of the most important advantages of this technique is its practical simplicity. However, a problem arises because 0-3 type composites consist of ceramics with similar compositions consolidated at relatively high temperatures. Because of the high degree of chemical intermixing, this high-temperature processing often leads to chemically inhomogeneous microstructures, which are not amenable to reliable reproduction.
Meanwhile, considerable efforts have been made to induce a crystallographic texture using the so-called templated grain-growth (TGG) technique, inspired by the work of Saito et al. ${ }^{13}$ Indeed, TGG allows the incorporation of well-aligned template crystals, the composition of which is different from that of matrix crystals. This technique provides an effective way to reduce $E_{\text {pol }}$ because the energy barrier for heterogeneous nucleation is generally smaller than that for homogeneous nucleation. However, it is difficult to achieve a high degree of texturing with typical TGG processes due to the relatively small aspect ratio of template crystals. It must be noted that the aspect ratio of typical layer-structured template crystals usually decreases significantly during topochemical reactions. ${ }^{14-16}$ In addition, the degree of texturing is critically dependent on the sintering time, which commonly exceeds tens of hours. The long sintering time hinders the use of volatile elements. ${ }^{15,17}$

Given that the hysteresis in IPS originates from ferroelastic domain reorientation during an electric-field-induced relaxor-to-ferroelectric transition, one possible solution is the optimal utilization of electrostriction while suppressing the relaxor-to-ferroelectric transition. ${ }^{4,18-20}$ It is known that $\left(\mathrm{Bi}_{1 / 2} \mathrm{Na}_{1 / 2}\right) \mathrm{TiO}_{3}$-based incipient piezoceramics exhibit a comparatively high electrostrictive coefficient. ${ }^{18,21}$ To observe 
a

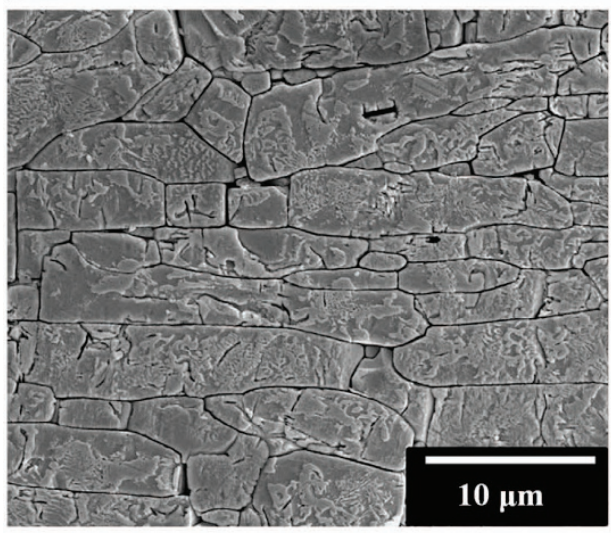

c

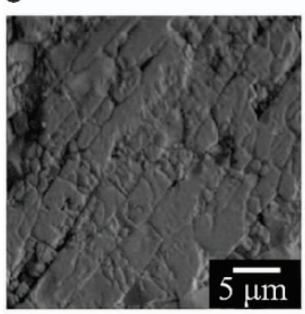

total ions

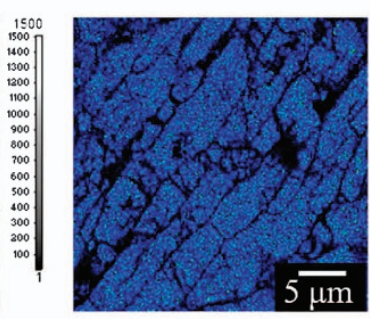

${ }^{23} \mathrm{Na}^{16} \mathrm{O}^{-}$ b

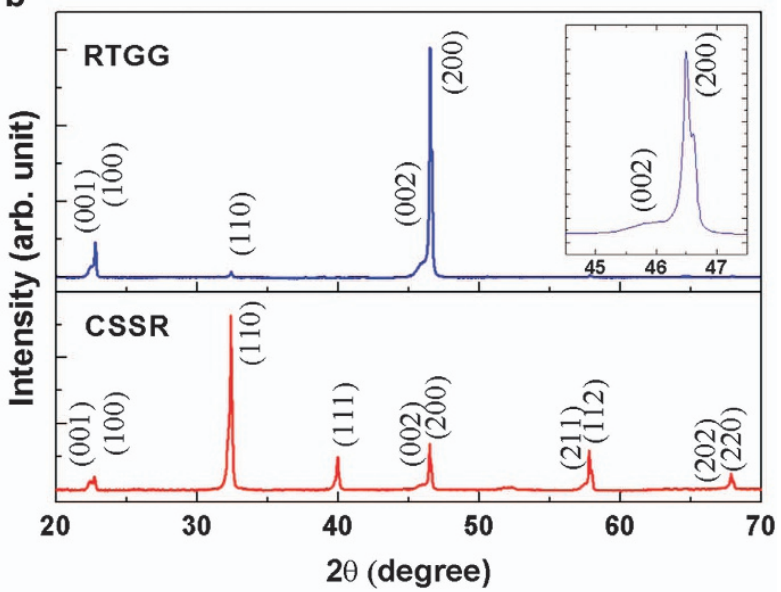

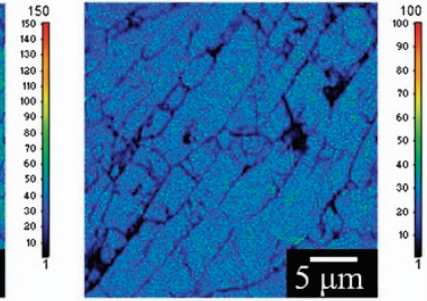

${ }^{48} \mathrm{Ti}^{16} \mathrm{O}-$

Figure 2 (a) Scanning electron microscopy image of the RTGG specimen sintered at $1150{ }^{\circ} \mathrm{C}$ for $10 \mathrm{~h}$. (b) X-ray diffraction profiles showing the profile change due to texture. The degree of texture is best reflected in the intensity change of (110). (c) A secondary ion mass spectrometry map of Na, Bi and Ti showing their homogeneous distribution throughout the specimen.

this effect as clearly as possible, we chose the ceramic $0.97 \mathrm{Bi}_{1 / 2}$ $\left(\mathrm{Na}_{0.78} \mathrm{~K}_{0.22}\right)_{1 / 2} \mathrm{TiO}_{3}-0.03 \mathrm{BiAlO}_{3}$ (BNKT-BA). ${ }^{22}$ This ceramic has moderate IPS, which therefore has room for further enhancement by the application of the currently proposed methodology. To ensure that the strain mechanism of the electrostrictive effect dominates over domain nucleation and reorientations, the polarization direction of the BNKT-BA was strongly constrained along the direction perpendicular to the electrodes by using highly anisotropic templates with a large aspect ratio $(>20$, see Supplementary Figure S1). Note that the electrostrictive effect becomes more pronounced when the contribution from domain reorientations vanishes. ${ }^{4}$ To provide the largest possible aspect ratio, a reactive templated grain-growth (RTGG) technique was implemented by omitting the topochemical reaction step. The results showed that suppressing the domain reorientation in the presence of electric fields markedly enhances the IPS by reinforcing the electrostrictive contribution to electromechanical strains.

\section{EXPERIMENTAL PROCEDURES}

\section{Preparation of $\mathrm{Na}_{0.5} \mathrm{Bi}_{4.5} \mathrm{Ti}_{4} \mathrm{O}_{15}$ (NBiT) templates}

To synthesize plate-shaped NBiT particles, $\mathrm{Na}_{2} \mathrm{CO}_{3}, \mathrm{Bi}_{2} \mathrm{O}_{3}$ and $\mathrm{TiO}_{2}(99.9 \%$ High Purity Chemicals, Tokyo, Japan) were mixed with $\mathrm{NaCl}$ (99\%, Sigma-Aldrich, St Louis, MO, USA), which was used as a flux to keep the oxide-to-salt ratio at a value of $1: 1$ by weight. This mixture was reacted at $1100^{\circ} \mathrm{C}$ for $4 \mathrm{~h}$. The product was washed more than 20 times with boiled deionized water to isolate the NBiT templates. The average diameter and thickness of the NBiT templates were $\sim 10 \mu \mathrm{m}$ and $0.5 \mu \mathrm{m}$, respectively, and the crystallographic $c$-axis was in the outof-plane direction of NBiT templates, as shown in Supplementary Figure S1.

\section{Preparation of BNKT-BA raw material}

The BNKT-BA matrix powders were synthesized using a conventional solid-state reaction method. Well-dried $\mathrm{Bi}_{2} \mathrm{O}_{3}, \mathrm{Na}_{2} \mathrm{CO}_{3}, \mathrm{~K}_{2} \mathrm{CO}_{3}, \mathrm{TiO}_{2}$ and $\mathrm{Al}_{2} \mathrm{O}_{3}$ (99.9\% High Purity Chemicals) were weighed to conform to the stoichiometry and then ball-milled for $24 \mathrm{~h}$ in ethanol using zirconia balls. The milled powder was calcined at $850^{\circ} \mathrm{C}$ for $2 \mathrm{~h}$ in a covered alumina crucible. The calcined and pulverized powder were mixed with an excess amount of $\mathrm{Na}_{2} \mathrm{CO}_{3}, \mathrm{~K}_{2} \mathrm{CO}_{3}, \mathrm{TiO}_{2}$ and $\mathrm{Al}_{2} \mathrm{O}_{3}$. The excess amounts were added to compensate the discrepancy between the composition of NBiT templates and the target composition. The resultant mixture was ball-milled again for $24 \mathrm{~h}$ and then calcined again at $700{ }^{\circ} \mathrm{C}$ for $1 \mathrm{~h}$.

Slurry preparation and sintering of textured BNKT-BA ceramic First, the solvent was prepared by mixing $60 \mathrm{vol} \%$ methyl ethyl ketone (99.5\%, MEK, Daejung Chemical \& Metals Co., Ltd, Siheung-Si, Korea) with $40 \mathrm{vol} \%$ ethyl alcohol (94\%, SK Chemical, Seongnam-Si, Korea). Then, polyvinyl butyral (BM-SZ, Sekisui Chemical Co., Ltd, Osaka, Japan), dibutyl phthalate (94\%, Daejung Chemical \& Metals Co., Ltd), and BYK-112 (BYK Chemical, Geretsried, Germany) were added in the slurry as a binder, a plasticizer and a dispersant, respectively. The slurry was mixed continuously for $24 \mathrm{~h}$. Then, $10 \mathrm{wt} \% \mathrm{NBiT}$ templates were added and the slurry was mixed again for $12 \mathrm{~h}$. The prepared slurry was tape-casted using a doctor blade to a uniform thickness of $80 \mu \mathrm{m}$ and then dried at room temperature. The green sheets were stacked and then pressed at $50{ }^{\circ} \mathrm{C}$ under a uniaxial pressure of $50 \mathrm{MPa}$ for $5 \mathrm{~s}$ to ensure firm adhesion between layers. Each sheet was laminated and cut to form a green compact. The green compacts were heated in air at $400{ }^{\circ} \mathrm{C}$ for $160 \mathrm{~h}$ to remove organic ingredients and then sintered in air at $1150^{\circ} \mathrm{C}$ for $10 \mathrm{~h}$. The choice of sintering time was based on our preliminary experiments on a ceramic of composition $0.985 \mathrm{Bi}_{1 / 2}\left(\mathrm{Na}_{0.78} \mathrm{~K}_{0.22}\right)_{1 / 2} \mathrm{TiO}_{3}-0.015 \mathrm{BiAlO}_{3}$, which is similar to the composition of the current material. As shown in Supplementary 
a
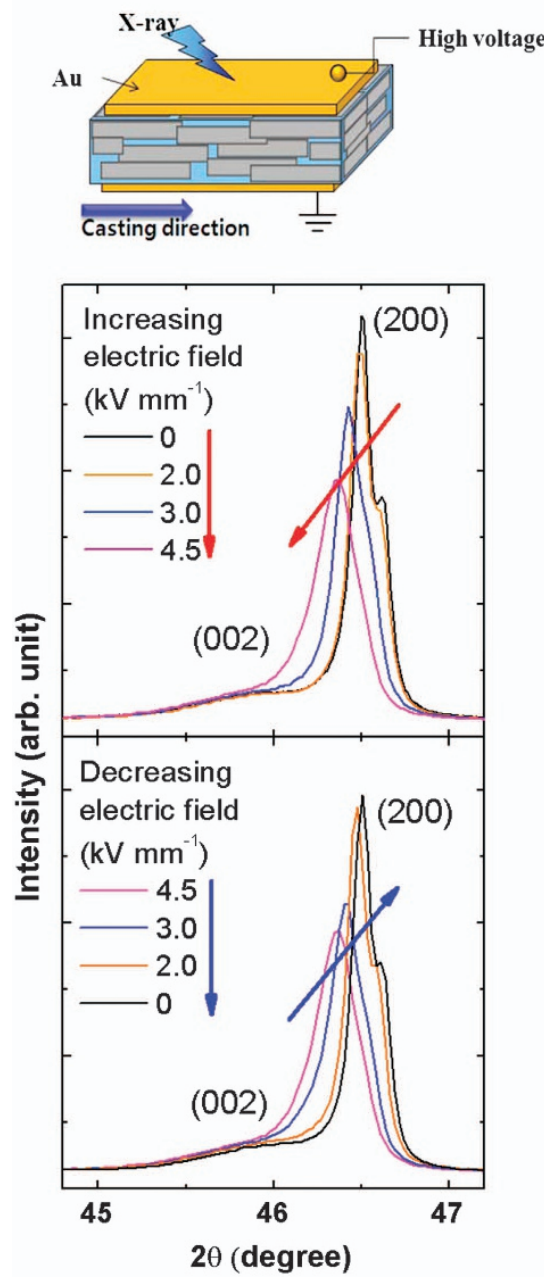

b

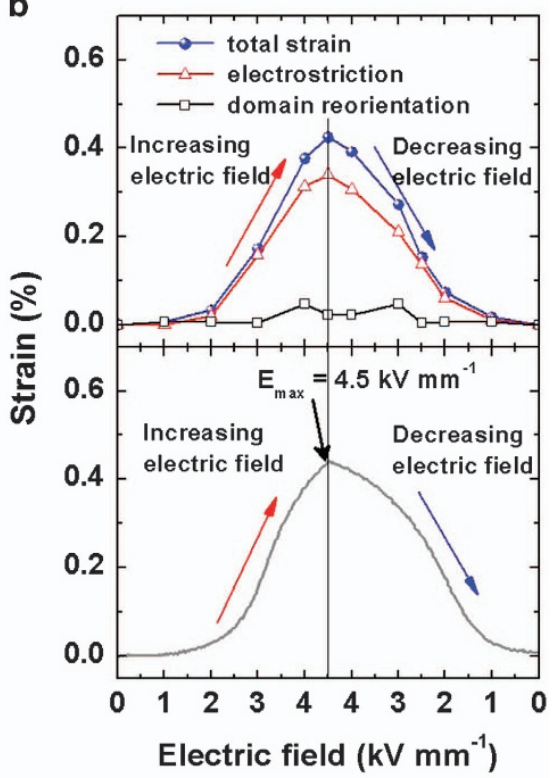

C

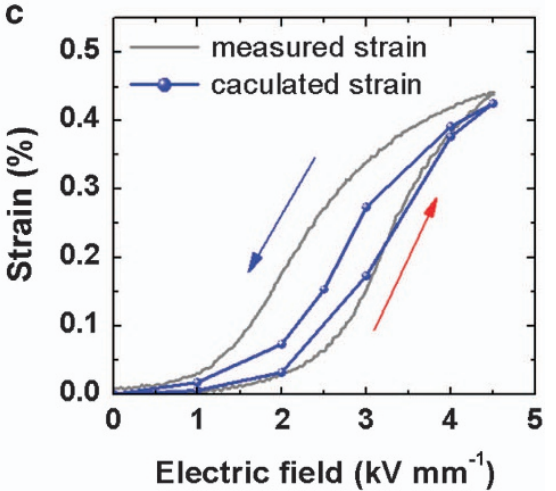

Figure 3 (a) In situ electric-field-dependent X-ray diffraction profiles at selected electric field levels, using a step function with the interval of $0.5 \mathrm{~h}$ for each step, and a schematically illustrated set-up. (b) Quantitative analyses, compared with the experimental strain (measured at $1 \mathrm{~Hz}$ ), reveal that the strain achieved at $4.5 \mathrm{kV} \mathrm{mm}^{-1}$ consists of $80 \%$ electrostriction and $20 \%$ domain reorientation. (c) A comparison of the experimental and the calculated profiles confirms that the strain response of the RTGG specimen can be largely attributed to electrostriction.

Figure S2, the maximum texture is achieved at $10 \mathrm{~h}$ of heat treatment. Randomly oriented BNKT-BA specimens were also prepared by the conventional method for comparison. ${ }^{22}$

\section{Sample characterization}

The phase identity, degree of texture and in situ electric-field-dependent structural transition were characterized by powder X-ray diffraction ( $X^{\prime}$ Pert-PRO, PANalytical, the Netherlands). Diffraction was performed on major surfaces, the normal vector of which was perpendicular to the casting direction. The microstructure of specimens was observed using field-emission scanning electron microscopy (FE-SEM, S-4200, Hitachi, Tokyo, Japan) on the fractured surfaces, which were perpendicular to the major surfaces after mirror-polishing and chemical etching. The compositional homogeneity was analyzed using a secondary ion mass spectrometer (Nano-SIMS 50 L, CAMECA, Gennevilliens, France) with a $\mathrm{Cs}^{+}$Gun at $16 \mathrm{keV}$ of impact energy and $0.4 \mathrm{pA}$.

Polarization and strain loops were measured in silicone oil using a piezoelectric evaluation system (aixPES-TF Analyzer 2000: aixPES, aixACCT Systems GmbH, Aachen, Germany) with a high-voltage amplifier (610E, TREK, NY).

\section{RESULTS AND DISCUSSION}

Figure la presents the state of the art in IPS in comparison to the results of the current study. The results demonstrate that harnessing electrostriction while the direction of polarization is kept perpendicular to the electric field is a highly effective way of tuning the electromechanical strain to the desired level. In addition to $E_{\text {pol }}$, the degree of hysteresis, defined as $\eta_{\text {hyst }}=\Delta S_{E=1 / 2 E_{\max }} / S_{E=E_{\max }} \times 100$, is also significantly reduced. It is noted that the strain achieved at a field as low as $4.5 \mathrm{kV} \mathrm{mm}^{-1}$ is $\sim 0.45 \%$, which is even larger than that of (001)-oriented $\mathrm{Pb}\left(\mathrm{Zn}_{1 / 3} \mathrm{Nb}_{2 / 3}\right) \mathrm{O}_{3} \quad(\mathrm{PZN})$ and $\mathrm{Pb}\left(\mathrm{Mg}_{1 / 3} \mathrm{Nb}_{2 / 3}\right) \mathrm{O}_{3^{-}}$ $0.24 \mathrm{PbTiO}_{3}(\mathrm{PMN}-0.24 \mathrm{PT})$ single crystals. ${ }^{23}$

Figure $1 \mathrm{~b}$ depicts the bipolar strain hysteresis loop with respect to the square of polarization. Evidently, there is a quadratic dependence of strain on polarization, implying that the strain originates from electrostriction. This result is further supported by the constricted polarization hysteresis loops (Supplementary Figure S3). ${ }^{2}$ Consistent with the common knowledge that the electrostrictive coefficient is temperature insensitive, ${ }^{24}$ it is seen that the temperature dependence of the electromechanical strain is far more stable in RTGG than in CSSR (Figure 1c and Supplementary Figure S4).

The room-temperature electrostrictive coefficient was determined to be $0.043 \mathrm{~m}^{4} \mathrm{C}^{-2}$, which is approximately two times greater than that of the CSSR specimen of the same composition $\left(\mathrm{Q}_{33}=0.026 \mathrm{~m}^{4} \mathrm{C}^{-2}\right)$. It is believed that this significant increase in the electrostrictive 
coefficient of the sample obtained by the RTGG process can be attributed to the suppression of domain reorientation; otherwise, the externally applied electric field would be dedicated exclusively to domain reorientation. ${ }^{4}$ With increasing temperature, the electrostrictive coefficient is observed to increase and is then saturated (Supplementary Figure S5), peaking at $0.049 \mathrm{~m}^{4} \mathrm{C}^{-2}$ at $140{ }^{\circ} \mathrm{C}$. This value is more than two times as large as that of the best-known BNT-based piezoceramics. Furthermore, it is highly comparable to that of lead-based single crystals (Figures 1d and e). ${ }^{4,21,25-30}$

Figure $2 \mathrm{a}$ presents a representative microstructure of an as-sintered RTGG specimen demonstrating a high degree of texture. It is interesting to see that every grain, without exception, shows clear ferroelectric domain contrast. This result implies that the origin of the currently observed IPS is not due to a relaxor-to-ferroelectric transition, although the same composition in CSSR specimens is an ergodic relaxor. ${ }^{22}$ The presence of domain contrast, that is, ferroelectric order, even in the absence of an external electric field, indicates that the grain size is sufficiently large for the polarization vector to be crystallographically bound to the templates, thus establishing a longrange order. $6,31,32$

A quantitative X-ray diffraction analysis of the degree of texture (Figure $2 b$ ) is characterized by the Lotgering factor of $95 \% .^{3}$ This value corresponds to one of the best textures induced in BNT-based piezoceramics thus far. It is important to note that the crystallographic orientation of the direction perpendicular to the casting direction is $<200>$ instead of [002], which is commonly targeted for tetragonal systems during the TGG process. Hence, the polarization vector of the final product is strongly excluded from the electric field direction during operation. Possible chemical inhomogeneity, caused by the use of templates of a chemically different composition, was checked by elemental mapping over several regions using a secondary ion mass spectrometer, as shown in Figure 2c. The results reveal that there is no visible chemical inhomogeneity, although the templates are richer in bismuth and more deficient in sodium than the target composition.

To clarify the underlying strain mechanism, in situ electric-fielddependent X-ray diffraction studies were performed (Figure 3a). It is interesting to see that when the electric field is applied, the (200) peak shifts significantly to lower angles, whereas the (002) peak remains practically unchanged. Profile fitting after stripping $K \alpha_{2}$ radiation (exemplarily shown in Supplementary Figure S6) revealed that other than the electrostrictive contribution, domain reorientation also contributes to the strain mechanism at fields above $3 \mathrm{kV} \mathrm{mm}^{-1}$. Domain reorientation contributes up to $\sim 20 \%$ of the strain value at the maximum electric field of $4.5 \mathrm{kV} \mathrm{mm}^{-1}$, as presented in Figure $3 \mathrm{~b}$. The unchanged magnitude of the unit cell vector $c$ in the electric-fielddriven reoriented domains may explain why the electrostrictive effect is significantly enhanced in the RTGG specimen. Here the polarization vector was designed not to be influenced by an external electric field. In this case, the existing local field due to the polarization vector may prevent the lattice from shrinking along the $c$ direction during electrostriction, forcing the field direction to expand further due to Poisson's ratio.

A comparison of the experimentally measured and calculated strain values reveals that the discrepancy between them is only significant for a decreasing electric field. Given that the peak position for (200) and (002) remains practically unchanged, regardless of the X-ray diffraction scan speed, the discrepancy in the hystereses of the measured and the calculated profiles in Figure $3 \mathrm{c}$ may be attributed to domain reorientation kinetics.

In summary, we have demonstrated that maximizing the potentially available electrostriction in relaxor-based materials is a highly effective way of overcoming three critical challenges in IPS, namely, large operation field, large hysteresis and large temperature dependence. To this end, we intentionally aligned the direction of polarization of the given material perpendicular to the direction of the electric field to minimize domain reorientations during operation. The current work opens up the possibility of applying incipient piezoceramics to real-world device applications by exploiting the merits of their exceptionally large displacements.

\section{CONFLICT OF INTEREST}

The authors declare no conflict of interest.

\section{ACKNOWLEDGEMENTS}

The work was supported by the Basic Science Research Programs (2015R1D1A3A01019470 and 2014R1A1A4A01004404) and Priority Research Centers Program (2009-0093818) through the National Research Foundation of Korea (NRF), funded by the Ministry of Education. YH and WJ acknowledge financial support from the Korea Institute of Energy Technology Evaluation and Planning (KETEP) and the Ministry of Trade, Industry \& Energy (MOTIE) of the Republic of Korea (No 20152020104960).

1 Zhang, S.-T., Kounga, A. B., Aulbach, E., Ehrenberg, H. \& Rödel, J. Giant strain in lead-free piezoceramics $\mathrm{Bi}_{0.5} \mathrm{Na}_{0.5} \mathrm{TiO}_{3}-\mathrm{BaTiO}_{3}-\mathrm{K}_{0.5} \mathrm{Na}_{0.5} \mathrm{NbO}_{3}$ system. Appl. Phys. Lett. 91, 112906 (2007)

2 Jo, W., Dittmer, R., Acosta, M., Zang, J., Groh, C., Sapper, E., Wang, K. \& Rödel, J. Giant electric-field-induced strains in lead-free piezoceramics for actuator applications status and perspective. J. Electroceram. 29, 71-93 (2012).

3 Hong, C.-H., Kim, H.-P., Choi, B.-Y., Han, H.-S., Son, J. S., Ahn, C. W. \& Jo, W. Lead-free piezoceramics - where to move on? J. Materiomics 2, 1-24 (2016).

4 Li, F., Jin, L., Xu, Z. \& Zhang, S. Electrostrictive effect in ferroelectrics: an alternative approach to improve piezoelectricity. Appl. Phys. Rev. 1, 011103 (2014).

5 Ahn, C. W., Hong, C.-H., Choi, B.-Y., Kim, H.-P., Han, H.-S., Hwang, Y., Jo, W., Wang, K., Li, J.-F., Lee, J.-S. \& Kim, I. W. A brief review on relaxor ferroelectrics and selected issues in lead-free relaxors. J. Kor. Phys. Soc. 68, 1481-1494 (2016).

6 Zhong, W. L., Wang, Y. G., Zhang, P. L. \& Qu, B. D. Phenomenological study of the size effect on phase transitions in ferroelectric particles. Phys. Rev. B 50, 698-703 (1994).

7 Bobnar, V., Kutnjak, Z., Pirc, R. \& Levstik, A. Electric-field-temperature phase diagram of the relaxor ferroelectric lanthanum-modified lead zirconate titanate. Phys. Rev. B 60, 6420-6427 (1999).

8 Jo, W., Schaab, S., Sapper, E., Schmitt, L. A, Kleebe, H.-J., Bell, A. J. \& Rödel, J. On the phase identity and its thermal evolution of lead free $\left(\mathrm{Bi}_{1 / 2} \mathrm{Na}_{1 / 2}\right) \mathrm{TiO}_{3}-6$ mol\% $\mathrm{BaTiO}_{3}$. J. Appl. Phys. 110, 074106 (2011).

9 Choi, S.-Y., Jeong, S.-J., Lee, D.-S., Kim, M.-S., Lee, J.-S., Cho, J. H., Kim, B. I. \& Ikuhara, Y. Gigantic electrostrain in duplex structured alkaline niobates. Chem. Mater. 24, 3363-3369 (2012).

10 Lee, D. S., Lim, D. H., Kim, M. S., Kim, K. H. \& Jeong, S. J. Electric field-induced deformation behavior in mixed $\mathrm{Bi}_{0.5} \mathrm{Na}_{0.5} \mathrm{TiO}_{3}$ and $\mathrm{Bi}_{0.5}\left(\mathrm{Na}_{0.75} \mathrm{~K}_{0.25}\right)_{0.5} \mathrm{TiO}_{3}-\mathrm{BiAlO}_{3}$. Appl. Phys. Lett. 99, 062906 (2011).

11 Lee, D.-S., Jeong, S. J., Kim, M. S. \& Koh, J. H. Electric field induced polarization and strain of Bi-based ceramic composites. J. Appl. Phys. 112, 124109 (2012).

12 Groh, C., Franzbach, D. J., Jo, W., Webber, K. G., Kling, J., Schmitt, L. A., Kleebe, H. J., Jeong, S.-J., Lee, J.-S. \& Rödel, J. Relaxor/ferroelectric composites: a solution in the quest for practically viable lead-free incipient piezoceramics. Adv. Funct. Mater. 24, 356-362 (2013).

13 Saito, Y., Takao, H., Tani, T., Nonoyama, T., Takatori, K., Homma, T., Nagaya, T. \& Nakamura, M. Lead-free piezoceramics. Nature 432, 84-87 (2004).

14 Hussain, A., Rahman, J. U., Ahmed, F., Kim, J.-S., Kim, M.-H., Song, T.-K. \& Kim, W.-J. Plate-like $\mathrm{Na}_{0.5} \mathrm{Bi}_{0.5} \mathrm{TiO}_{3}$ particles synthesized by topochemical microcrystal conversion method. J. Eur. Ceram. Soc. 35, 919-925 (2015).

15 Zhang, H., Xu, P., Patterson, E., Zang, J., Jiang, S. \& Rödel, J. Preparation and enhanced electrical properties of grain-oriented $\left(\mathrm{Bi}_{1 / 2} \mathrm{Na}_{1 / 2}\right) \mathrm{TiO}_{3}$-based lead-free incipient piezoceramics. J. Eur. Ceram. Soc. 35, 2501-2512 (2015).

16 Jiang, C., Zhou, X., Zhou, K., Chen, C., Luo, H., Yuan, X. \& Zhang, D. Grain oriented $\mathrm{Na}_{0.5} \mathrm{Bi}_{0.5} \mathrm{TiO}_{3}-\mathrm{BaTiO}_{3}$ ceramics with giant strain response derived from singlecrystalline $\mathrm{Na}_{0.5} \mathrm{Bi}_{0.5} \mathrm{TiO}_{3}-\mathrm{BaTiO}_{3}$ templates. J. Eur. Ceram. Soc. 36 1377-1383 (2016).

17 Lee, D.-S., Jeong, S.-J., Park, E.-C. \& Song, J.-S. Characteristic of grain oriented $\left(\mathrm{Bi}_{0.5} \mathrm{Na}_{0.5}\right) \mathrm{TiO}_{3}-\mathrm{BaTiO}_{3}$ ceramics. J. Electroceram. 17, 505-508 (2006).

18 Ang, C. \& Yu, Z. High, purely electrostrictive strain in lead-free dielectrics. Adv. Mater. 18, 103-106 (2006). 
19 Wang, X., Xu, C.-N., Yamada, H., Nishikubo, K. \& Zheng, X.-G. Electro-mechano-optical conversions in $\mathrm{Pr} 3+$-doped $\mathrm{BaTiO}_{3}-\mathrm{CaTiO}_{3}$ ceramics. Adv. Mater. 17, 1254-1258 (2005).

20 Zuo, R., Qi, H., Fu, J., Li, J., Shi, M. \& Xu, Y. Giant electrostrictive effects of $\mathrm{NaNbO}_{3}$ $\mathrm{BaTiO}_{3}$ lead-free relaxor ferroelectrics. Appl. Phys. Lett. 108, 232904 (2016).

21 Zhang, S.-T., Kounga, A. B., Jo, W., Jamin, C., Seifert, K., Granzow, T., Rödel, J. \& Damjanovic, D. High-strain lead-free antiferroelectric electrostrictors. Adv. Mater. 21 4716-4720 (2009).

22 Ullah, A., Ahn, C. W., Hussain, A., Lee, S. Y., Lee, H. J. \& Kim, I. W. Phase transitions and large electric field-induced strain in $\mathrm{BiAlO}_{3}$-modified $\mathrm{Bi}_{0.5}(\mathrm{Na}, \mathrm{K})_{0.5} \mathrm{TiO}_{3}$ lead-free piezoelectric ceramics. Curr. Appl. Phys. 10, 1174-1181 (2010).

23 Park, S.-E. \& Shrout, T. R. Ultrahigh strain and piezoelectric behavior in relaxor based ferroelectric single crystals. J. Appl. Phys. 82, 1804-1811 (1997).

24 Kuwata, J., Uchino, K. \& Nomura, S. Electrostrictive coefficients of $\mathrm{Pb}\left(\mathrm{Mg}_{1 / 3} \mathrm{Nb}_{2 / 3}\right) \mathrm{O}_{3}$ ceramics. Jpn. J. Appl. Phys. 19, 2099-2103 (1980).

25 Kang, D. H., Lee, Y. H. \& Yoon, K. H. Phase transition, dielectric and electrostrictive behaviors in (1 - x)PYN- xPMN. J. Mater. Res. 13, 984-989 (1998).

26 Sheets, S. A., Soukhojak, A. N., Ohashi, N. \& Chiang, Y.-M. Relaxor single crystals in the $\left(\mathrm{Bi}_{1 / 2} \mathrm{Na}_{1 / 2}\right)_{1-x} \mathrm{Ba}_{x} \mathrm{Zr}_{y} \mathrm{Ti}_{1-\mathrm{y}} \mathrm{O}_{3}$ system exhibiting high electrostrictive strain. J. Appl. Phys. 90, 5287-5295 (2001).

27 Zhang, S.-T., Yan, F., Yang, B. \& Cao, W. Phase diagram and electrostrictive properties of $\mathrm{Bi}_{0.5} \mathrm{Na}_{0.5} \mathrm{TiO}_{3}-\mathrm{BaTiO}_{3}-\mathrm{K}_{0.5} \mathrm{Na}_{0.5} \mathrm{NbO}_{3}$ ceramics. Appl. Phys. Lett. 97, 122901 (2010)

28 Hao, J., Bai, W., Li, W., Shen, B. \& Zhai, J. Phase transitions, relaxor behavior, and electrical properties in $(1-\mathrm{x})\left(\mathrm{Bi}_{0.5} \mathrm{Na}_{0.5}\right) \mathrm{TiO}_{3}-\mathrm{x}\left(\mathrm{K}_{0.5} \mathrm{Na}_{0.5}\right) \mathrm{NbO}_{3}$ lead-free piezoceramics. J. Mater. Res. 27, 2943-2955 (2012).
29 Han, H.-S., Jo, W., Kang, J.-K., Ahn, C.-W., Won Kim, I., Ahn, K.-K. \& Lee, J.-S. Incipient piezoelectrics and electrostriction behavior in $\mathrm{Sn}$-doped $\mathrm{Bi}_{1 / 2}\left(\mathrm{Na}_{0.82} \mathrm{~K}_{0.18}\right)_{1 / 2}$ $\mathrm{TiO}_{3}$ lead-free ceramics. J. Appl. Phys. 113, 154102 (2013).

$30 \mathrm{Li}, \mathrm{F}$., Jin, L., Xu, Z., Wang, D. \& Zhang, S. Electrostrictive effect in $\mathrm{Pb}\left(\mathrm{Mg}_{1 / 3} \mathrm{Nb}_{2 / 3}\right) \mathrm{O}_{3^{-}}$ x $\mathrm{PbTiO}_{3}$ crystals. Appl. Phys. Lett. 102, 152910 (2013).

31 Jiménez, R., Amorín, H., Ricote, J., Carreaud, J., Kiat, J. M., Dkhil, B., Holc, J., Kosec, M. \& Algueró, M. Effect of grain size on the transition between ferroelectric and relaxor states in $0.8 \mathrm{~Pb}\left(\mathrm{Mg}_{1 / 3} \mathrm{Nb}_{2 / 3}\right) \mathrm{O}_{3}-0.2 \mathrm{PbTiO}_{3}$ ceramics. Phys. Rev. B 78, 094103 (2008).

32 Hoshina, T., Furuta, T., Yamazaki, T., Takeda, H. \& Tsurumi, T. Grain size effect on dielectric properties of $\mathrm{Ba}(\mathrm{Zr}, \mathrm{Ti}) \mathrm{O}_{3}$ ceramics. Jpn. J. Appl. Phys. 51, 09LC04 (2012)

\section{(c) (i)}

This work is licensed under a Creative Commons Attribution 4.0 International License. The images or other third party material in this article are included in the article's Creative Commons license, unless indicated otherwise in the credit line; if the material is not included under the Creative Commons license, users will need to obtain permission from the license holder to reproduce the material. To view a copy of this license, visit http:// creativecommons.org/licenses/by/4.0/

(C) The Author(s) 2017

Supplementary Information accompanies the paper on the NPG Asia Materials website (http://www.nature.com/am) 